\title{
Evaluation of the role of substrate and albumin on Pseudomonas aeruginosa biofilm morphology through FESEM and FTIR studies on polymeric biomaterials
}

\author{
S. Dutta Sinha ${ }^{1} \cdot$ Susmita Chatterjee $^{3} \cdot$ P. K. Maiti $^{3} \cdot$ S. Tarafdar ${ }^{1}$. \\ S. P. Moulik ${ }^{2}$
}

Received: 24 October 2016/Accepted: 5 January 2017/Published online: 2 February 2017

(C) The Author(s) 2017. This article is published with open access at Springerlink.com

\begin{abstract}
Bacterial biofilms pose the greatest challenge to implant surgeries leading to device-related infections and implant failure. Our present study aims at monitoring the variation in the biofilm architecture of a clinically isolated strain and ATCC 27853 strain of Pseudomonas aeruginosa on two polymeric biomaterials, used in implants. The perspective of our study is to recognize the potential of these two biomaterials to create biofilm infections and develop the understanding regarding their limitations of use and handle patients with this deeper insight. The final goal, however, is an accurate interpretation of substratemicrobe interactions in the two biomaterials, which will provide us the knowledge of possible surface modifications to develop of an efficacious anti-biofilm therapy for
\end{abstract}

deterring implant infections. The reference strain ATCC 27853 and a clinical isolate of $P$. aeruginosa collected from urinary catheters of patients suffering from urinary tract infections, have been used as microbes while clinical grades of polypropylene and high density polyethylene, have been used as 'substrates' for biofilm growth. The variation in the nature of the 'substrate' and 'conditioning layer' of BSA have been found to affect the biofilm architecture as well as the physiology of the biofilmforming bacteria, accompanied by an alteration in the nature and volume of EPS (extracellular polysaccharide) matrices.
Electronic supplementary material The online version of this article (doi:10.1007/s40204-017-0061-2) contains supplementary material, which is available to authorized users.

\section{S. Dutta Sinha}

ju.research@gmail.com

1 Department of Physics, Jadavpur University, Kolkata 700032, India

2 Centre for Surface Science, Department of Chemistry, Jadavpur University, Kolkata 700032, India

3 Department of Microbiology, SSKM Hospital-Institute of Postgraduate Medical Education and Research, Kolkata 700020, India 


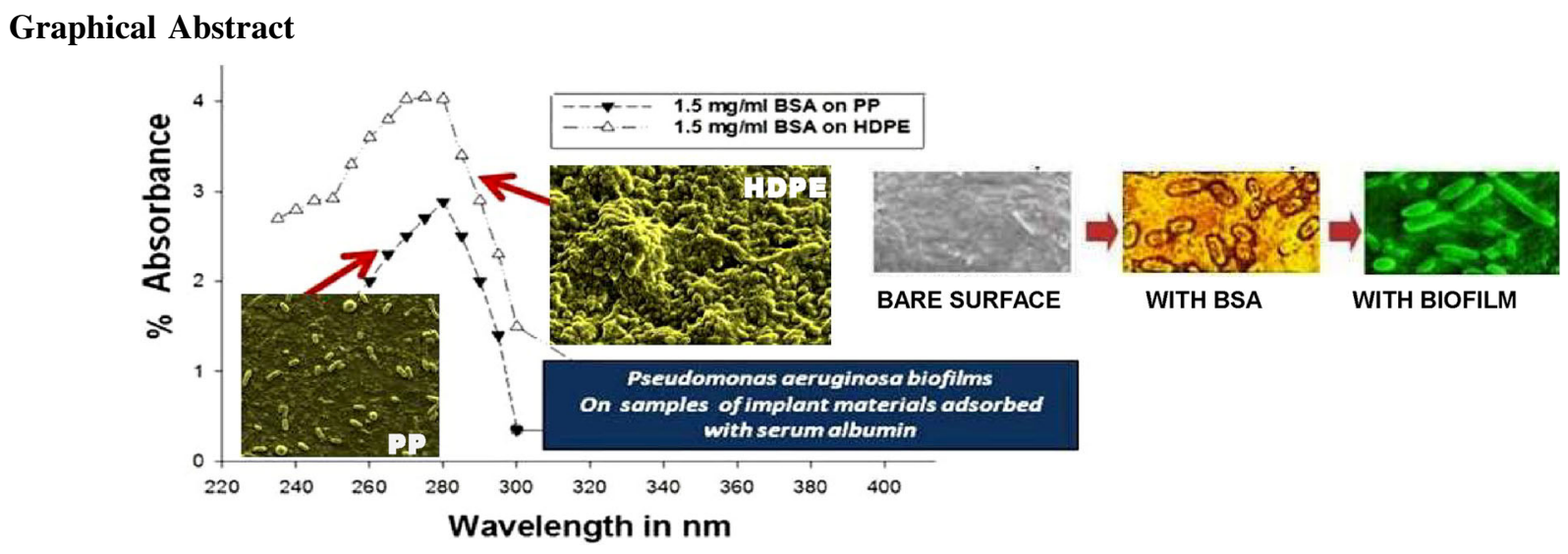

Keywords Biofilms · Biomaterials · Adsorption · Bacteria $\cdot$ Proteins $\cdot$ Conditioning layer

\section{Introduction}

Indwelling medical devices such as catheters, heart valves, vascular bypass grafts, ocular lenses, artificial joints, cardiac stents, and central nervous shunts have become an integral and indispensable part of modern day clinical practice. These devices are responsible for reducing mortality and improving quality of life of patient. Unfortunately, submerged surfaces of these devices act as excellent seat for microbial biofilms (Donlan 2001; Costerton et al. 1999). The physicochemical forces that mediate bacterial adhesion can be divided into two time-dependent phases (Fig. 1). Phase I involves reversible bacterial attachment with the surface over the first $1-2 \mathrm{~h}$ post-implantation which is mediated through long-range (e.g., gravitational, van der Waals, and electrostatic interactions) and short-range (e.g., hydrogen bonding, dipole-dipole, ionic, and hydrophobic interactions) forces (Hori and Matsumoto 2010). Phase II begins approximately $2-3 \mathrm{~h}$ later, which is characterized by stronger adhesion between the bacteria and the implanted biomaterial resulting in irreversible molecular bridging (Li et al. 2012). Beyond Phase II, only certain bacterial strains are capable of forming a biofilm, when appropriately supplied with water and nutrients. Biofilms are consortium of surface adhered bacteria, which are embedded in a self-secreted matrix of extracellular polymeric substances (EPS) (Flemming et al. 2007; Flemming and Wingender 2010; $\mathrm{Vu}$ et al. 2009; Branda et al. 2005; Haggag 2010; Alpkvist et al. 2006; Wingender et al. 2012). Bacteria within biofilm are extremely resistant to actions of antimicrobials (Stewart and Costerton 2001; Mah and O'Toole 2001; Høiby et al. 2010) and can evade host immune reaction (Hornef et al. 2002; Foster 2005), making device-associated biofilm infections extremely difficult to treat (Weinstein and Darouiche 2001; von Eiff et al. 2005; Lynch and Robertson 2008).

The Gram negative bacterium Pseudomonas aeruginosa, an opportunistic pathogen (Whiteley et al. 2001; Campa et al. 2012; Oberhardt et al. 2008), is one of the most prevalent colonizer of medical devices in immunocompromised patients (Kiehn and Armstrong 1990; RoyBurman et al. 2001; Falkinham et al. 2015; Waldvogel and Bisno 2000). The objectives of the study were to evaluate the proneness of the surfaces of two widely used biomaterials toward biofilm formation, and identify the roles of implant surface and conditioning layer in modulating the biofilm architecture. The ultimate aim was, however, to gain an insight of the substrate-microbe interactions on the implant surfaces (Tuson and Weibel 2013; Dang and Lovell 2016; Salta et al. 2013; Hori and Matsumoto 2010), to enable the tailoring of surface properties, to control the emergence of biofilm formation on these surfaces, and potentially avoiding the occurrence of peri-implant infections. The field emission scanning electron microscopy (FE-SEM) has been used as a prime investigating tool and FTIR analysis was performed to compare the difference in the bacterial accumulation in the biofilms of the clinical and reference strains of $P$. aeruginosa on a single biomaterial surface.

Any solid surface when immersed in an aquatic environment gets adsorbed with the neighboring dissolved organic matter. Such a situation is similar to the placement of a biomaterial implant inside a biological fluid such as blood, plasma or urine which is followed by subsequent adsorption of proteins to the biomaterial surface (Huang et al. 2000; Rios et al. 2007). The adsorbed layer is defined as the 'conditioning layer' or 'molecular film' (Compere et al. 2001; Bakker et al. 2003; Bhosle et al. 2005; Garrett et al. 2008). The formation of the 'conditioning layer' modifies the surface characteristics of the bare biomaterial surface, due to change in its physical properties such as surface charge, wettability, hydrophobicity, and surface roughness (Amiji and Park 1993; Dewez et al. 1999; 
Hetrick and Schoenfisch 2006; Chu et al. 2002). All subsequent biological responses of the biomaterial surface, including antigenic response, attachment, and growth of cells and thrombosis, depend critically on the layer of adsorbed protein (Vogler 2012; Castner and Ratner 2002).

The effect of turbulence on nitrifying biofilms was studied in cylindrical PVC reactors (Kugaprasatham et al. 1992). Some of the approaches to limit bacterial colonization have focused on chemical degradation of stably adhered bacteria, including surface functionalization with microbicidal agents (Chang and Merritt 1992; Tiller et al. 2002). It was observed that the parameters defining substrate flux and biofilm structure (areal density, filament height, and cross-sectional area of filament) are inter-related parameters and are strongly affected by turbulence near the biofilm. In contrast to the widely held view that microorganisms respond rapidly to changes in environmental conditions, it has been observed (Freeman and Lock 1995) that the microbes in biofilms appear remarkably resilient to substantial changes in dissolved high-molecular-weight materials as it did not affect bacterial densities or the synthesis of phospholipids and DNA. The effect of different substrate loading rates and shear stresses on thickness, roughness, and density of mono-population Pseudomonas aeruginosa biofilms was observed by growing in an annular reactor (Peyton 1996). The effects of substrate and $\mathrm{pH}$ on biofilm nitrification were studied using a microelectrode technique and a micro-slicing technique (Zhang et al. 1999). It has been observed that numerous conditions, such as surface and interface properties, nutrient availability, the composition of the microbial community, and hydrodynamics, can affect biofilm structure (Stoodley et al. 1997). It has also been observed that under high shear stresses, such as on the surface of teeth during chewing, the biofilm (dental plaque) is typically stratified and compacted (Bowden et al. 1997; Wimpenny and Colasanti 1997). Efforts of controlling microbial biofilms on surfaces have been tried by surface impregnation with slow-releasing biocides such as gold or silver (Lee et al. 2005; Li et al. 2006; Saygun et al. 2006; Hetrick and Schoenfisch 2006) and antibiotics (Chang and Merritt 1992; Kohnen et al. 2003) or surface functionalization of specific antimicrobial peptides and polymers (Tiller et al. 2002; Etienne et al. 2005; Ignatova et al. 2006; Rudra et al. 2006). Since biofilm formation requires an initial stable attachment of a viable microbial population on a surface, a promising approach to limiting microbial colonization is prevention of bacterial adhesion to material substrata prior to colonization. Others have reported that poly(ethylene glycol)-conjugated polypeptides confer adhesion resistance and hypothesized that such results may be due to high degrees of substrata surface hydration (Boulmedais et al. 2004).
The effect of antimicrobials and alkali on biofilms was studied for different bacteria isolated from root canals with persistent infections (de Paz et al. 2010) with the help of confocal microscopy and a mini flow cell system, which was followed by image analysis. The biofilm system developed by them was sensitive to antimicrobials commonly used in endodontics but the effects were substratumdependent, and most organisms displayed increased resistance to the antimicrobials on collagen-coated surfaces. The influence of glucose concentration and flow velocity on the distribution of effective diffusivity in biofilms was evaluated (Beyenal and Lewandowski 2000). It was observed that the Coulombic efficiency (CE) and power output from microbial fuel cells varied with different substrates, while the bacterial viability was similar for all the systems (Chae et al. 2009). It was noted that with increasing substrate $\mathrm{COD} / \mathrm{N}$ ratios, the specific oxygen utilization rates of nitrifying bacteria in biofilm were found to decrease, indicating that nitrifying population became less dominant (Liu et al. 2010). It has been demonstrated (Zhu et al. 2004) that nitrate can serve both as a growthcontrolling nutrient and as an electron acceptor in a biofilm for the respiration of VOCs with low Henry's constants. Ammonium and nitrite are two substrates of anammox bacteria, but they are also inhibitors under high concentrations. The performance of two anaerobic ammoniumoxidizing (anammox) upflow biofilm (UBF) reactors was investigated (Tang et al. 2010). It was found that ammonium and nitrite are two substrates of anammox bacteria, but they are also inhibitors under high concentrations. Investigating the potential utility of d-amino acids in preventing device-related infections, it has been shown (Hochbaum et al. 2011) that surfaces impregnated with d-amino acids were effective in preventing biofilm growth. The initial biofilm formation on $\mathrm{Ti}$ implant surfaces with different micro-topography and hydrophilicity has been examined (Almaguer-Flores et al. 2012; Li et al. 2012), which reveal that initial biofilm formation and composition are affected by surface micro-topography and hydrophilicity.

It can be stated more generally that the development of a versatile and comprehensive approach to reduce stable bacterial adhesion to surfaces has been limited by incomplete understanding of the regulating physicochemical material properties and factors involved in the substrate-microbe interactions.

\section{Experimental}

The present study focuses on the modulation of biofilm architecture of a clinical strain and a reference strain of $P$. aeruginosa (ATCC 27853), in relation to the interfacial 
properties of two polymeric biomaterials, which are widely used in implants and indwelling medical devices.

In our experiment, we have defined 'substrate' as the surface of the biomaterial on which the biofilms are formed. This may be the bare surface of the biomaterial or the biomaterial surface adsorbed with BSA. The biomaterials, polypropylene (PP) used in a venous catheters and other indwelling medical devices and high density polyethylene (HDPE), frequently used in orthopedic implants have been used in our experiments as substrates for biofilm growth while the serum protein BSA is used as the adsorbate. Albumin (BSA in our case) has been chosen as the adsorbate, since concentration of serum albumin in the plasma is among the highest and ranges from 35 to $50 \mathrm{mg} /$ $\mathrm{mL}$, while it is only $0-5 \mathrm{pg} / \mathrm{mL}$ for interleukin 6 . Also, according to Vroman effect (Leonard and Vroman 1992), albumin is one of the initial components to get adsorbed on an implant surface after its introduction at the implant site.

Though biofilms have been studied in detail from a variety of perspectives, the modulation in the patterns of biofilm formation in correspondence with properties of substrate or conditioning layer has never been duly characterized. Our research reveals that the architecture of biofilm formation by a single strain of bacteria varies in response to alteration of substrate and conditioning layer. The study consists of two parts: (1) adsorption of BSA on biomaterial surface to generate a conditioning layer (2) comparison of the morphologies of biofilms of a clinically isolated strain and a reference strain of $P$. aeruginosa on multiple biomaterials, widely used in implants.

\section{Biomaterials and production of the conditioning layer}

Commercially available PP and HDPE having machined finish were obtained in square configuration $(10 \mathrm{~mm} \times 10 \mathrm{~mm})$ from Plastic Abhiyanta Ltd, India. PP is used in a variety of catheters except urinary catheters, while HDPE is widely used in orthopedic implants. The water used in all our experiments was of HPLC grade (Lichrosolv) from Merck, India. Tris buffer was obtained from Sigma-Aldrich, USA while BSA was from MP Biomedical Ltd, USA. The polymer chips were initially cleaned in an ultrasonic cleaner, rinsed with water, autoclaved, blow dried, and preserved in a vacuum desiccator for adsorption experiments.

BSA was mixed in two different proportions with buffer solutions of $\mathrm{pH} 7.4$ (concentration were $0.5 \mathrm{mg} / \mathrm{ml}$ and $1.5 \mathrm{mg} / \mathrm{ml}$ ) and left for about a week with intermittent mixing to dissolve the BSA completely. BSA solution of a specific concentration was taken in six separate glass vials each containing a single chip for $9,12,15,18,21$, and $24 \mathrm{~h}$. These times are termed as exposure time ' $\tau$ ' whose maximum $\left(\tau^{\max }\right)$ and minimum $\left(\tau^{\min }\right)$ were 24 and $9 \mathrm{~h}$, respectively. After the stipulated time, the chips were removed from the protein solutions, rinsed with water, and finally blow-dried and preserved in a desiccator ready for growing biofilms. The chips obtained from adsorption experiments possess different degrees of BSA adsorbed on them, which is termed as the conditioning layer, and could not be sterilized further to prevent the denaturation of the adsorbed protein. The chips preserved in our experiments for the growth of biofilms were all adsorbed with [BSA] of $1.5 \mathrm{mg} / \mathrm{ml}$ to standardize the 'conditioning layer'.

The BSA solutions obtained from adsorption experiments after the removal of each chip were preserved for at $4{ }^{\circ} \mathrm{C}$ for absorbance measurements. The UV absorbance was measured in a Shimadzu 2550 UV/VIS Spectrophotometer (Shimadzu, Japan) in matched $3.0 \mathrm{~cm}$ quartz cells.

\section{Bacterial strain and culture condition}

One strong biofilm-forming clinical strain of $P$. aeruginosa isolated from the surface of a uro-catherter used for a prolonged period of time and one reference strain of $P$. aeruginosa ATCC 27853 were included in the study. After thawing, the frozen culture was adjusted to 0.5 McFarland standards. This suspension was diluted 1:100 and $1 \mathrm{ml}$ was used to inoculate $100 \mathrm{ml}$ of sterile LB broth (Luria Bertanii Agar (LBB) obtained from Himedia, India). The bacteria grown overnight in LBB at $37{ }^{\circ} \mathrm{C}$ were diluted in the same broth to an optical density of 0.5 at $600 \mathrm{~nm}$ and used as inoculums for biofilm study.

\section{Growing of biofilms}

The treated and untreated chips were placed in the wells of 24 well tissue culture plate and $1 \mathrm{ml}$ of bacterial culture (O.D 0.5 at $600 \mathrm{~nm}$ ) were added to each well. Each 24 well plate contained a separate set of chips with a definite adsorption time and each system was closed and sealed without addition or removal of any component with the exception of broth. The sterile LBB was added carefully from time to time to avoid desiccation and incubated at $37{ }^{\circ} \mathrm{C}$ for 7 days with shaking at $180 \mathrm{rpm}$. Each set of experiment was performed on triplicate. The plates were sealed and placed on the shaker plate of the BOD incubator set at $180 \mathrm{rpm}$ and rotated simultaneously for 7 days. Care was taken to ensure that each plate was in upright position during rotation, without tilting, which might affect the growth condition of the biofilms. After the entire 7-day growth period, the polymer chips were aseptically removed and washed thrice with phosphate buffered saline (PBS pH 7.2) to remove planktonic bacteria. Chips were then air dried and prepared for FESEM measurements. 
The above protocol for biofilm growth was repeated for the reference strain of $P$. aeruginosa ATCC 27853 and the chips with biofilms were also prepared for FESEM measurements.

\section{Sample preparation for FE-SEM}

The chips with attached bacterial cells were covered with $2.5 \%$ glutaraldehyde and kept for $3 \mathrm{~h}$ in $4{ }^{\circ} \mathrm{C}$ after which they were washed thrice with the phosphate buffer solution. They were then passed once through the graded series of alcohol $(25,50$ and $75 \%$, twice through $100 \%$ ethanol) each for $10 \mathrm{~min}$, finally transferred to the critical point drier and kept overnight to make them ready for biofilm analysis.

To compare the architecture of the biofilms produced by the clinically isolated strain of $P$. aeruginosa on different substrates after 7 days, FESEM measurements were conducted at $2.0-10 \mathrm{kV}$ in a field emission scanning electron microscope (FESEM: Inspect F50, FEI Europe BV, and The Netherlands; FP 2031/12, SE Detector R580). For this purpose, the dried polymer chips with and without biofilms were sputter-coated with a 3-nm-thick conductive layer of gold. We have used Image $\mathbf{J}$ for analysis of the SEM images.

\section{Results}

\section{Adsorption experiments}

The BSA solution preserved in each vial after removal of the polymer chips obtained from "Biomaterials and production of the conditioning layer" section was subjected to absorbance measurements in a UV-visible spectrophotometer. For all solutions, peaks of absorbance at 270-280 nm with varying intensities were observed. Considering a particular polymer, say PP (Figure SI 1, Supplementary Information) for a fixed exposure time, absorbance was found to be higher for higher initial [BSA].

Hence, higher absorbance implied higher concentration of residual BSA solutions, which has been verified by our experimental results. Higher exposure time had a

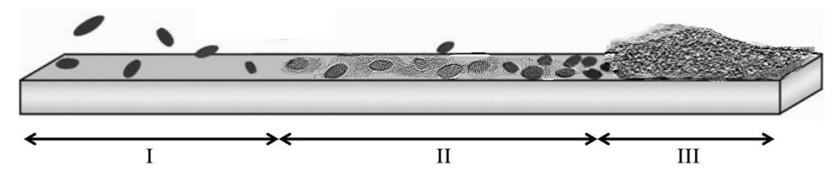

Fig. 1 Stages of bacterial attachment to a biomaterial surface. I Adhesion of bacteria to biomaterial involves reversible cellular association with the surface. II Strong bacterial adhesion due to irreversible molecular bridging through cell surface adhesin compounds. III Biofilm formation decreasing effect on the absorbance at each initial concentration. Thus, at each [BSA], higher exposure time produced more adsorption of the protein on to the surface of the polymer chips proving that the adsorption of BSA was proportional to [BSA] in solution for the same exposure time irrespective of the mechanism of adsorption involved.

Comparison between the absorbance peaks of PP and HDPE (Figure SI 2, Supplementary Information) having the same adsorption time (both $18 \mathrm{~h}$ ), and equal [BSA] showed higher peaks of the latter compared to the former. Thus, we can conclude that under similar conditions of pressure, temperature, and $\mathrm{pH}$, the adsorption of BSA was higher on the surface of PP than on HDPE.

\section{Growth of biofilms}

\section{Effect of substrate}

The FESEM images of the biofilms formed by the clinical and ATCC strains of $P$. aeruginosa on a pristine PP surface adsorbed with BSA for $9 \mathrm{~h}$ are shown in Fig. 2. The spread-out nature is common to both biofilms in Fig. 2a, b, citing a similarity in response of the two strains of bacteria to the same substrate (i.e., PP surface with conditioning layer of BSA) regarding biofilm adhesion. Though both biofilms are 7 days old, in the former image (Fig. 2a) bacteria are found dispersed from the mature biofilm (shown with black arrow), but in the latter (Fig. 2b) biofilm architecture is such that all bacteria remain concealed. Pores and channels are characteristic of the biofilm in Fig. 2a, while biofilm of Fig. $2 b$ is significantly dominated by flat surfaces (resembling salt flats), with the presence of $\mathrm{NaCl}$ as indicated by EDAX studies (Fig SI 3, Supplementary Information).

The presence of the bacteria concealed within the biofilm of almost flat topography was revealed through FT-IR data (Fig. 3) showing presence of nucleic acids (Jiao et al. 2010). It is evident from the comparison of FT-IR data of EPS matrices of the respective strains of bacteria that very little/no differences do exist between them with regard to their chemical composition, proportion of each chemical constituent but significantly in the amount of bacteria embedded within the respective biofilms. We have not performed a detailed analysis of FTIR data here, but a glimpse of the similarity and differences is only provided to verify the effect of different bacteria on a single substrate. However, the FE-SEM images in Fig. 2a, b reveal almost identical spreading and adhesion of the EPS matrices of both strains on the BSA-adsorbed PP surface.

A similar comparison of FE-SEM images of the biofilms formed by the clinical and ATCC strains of $P$. aeruginosa, on a pristine HDPE surface adsorbed with BSA for $24 \mathrm{~h}$ is 
Fig. 2 FESEM images on PP surface adsorbed with BSA for 24 h by Pseudomonas aeruginosa a clinical strain and b reference strain ATCC 27853

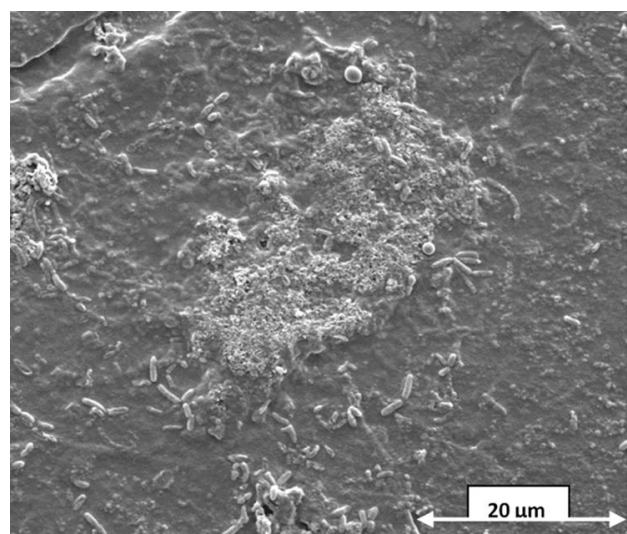

(a)

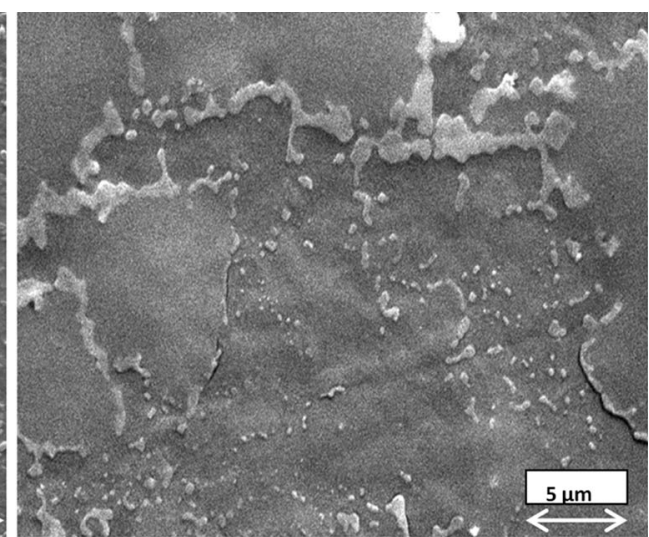

(b)

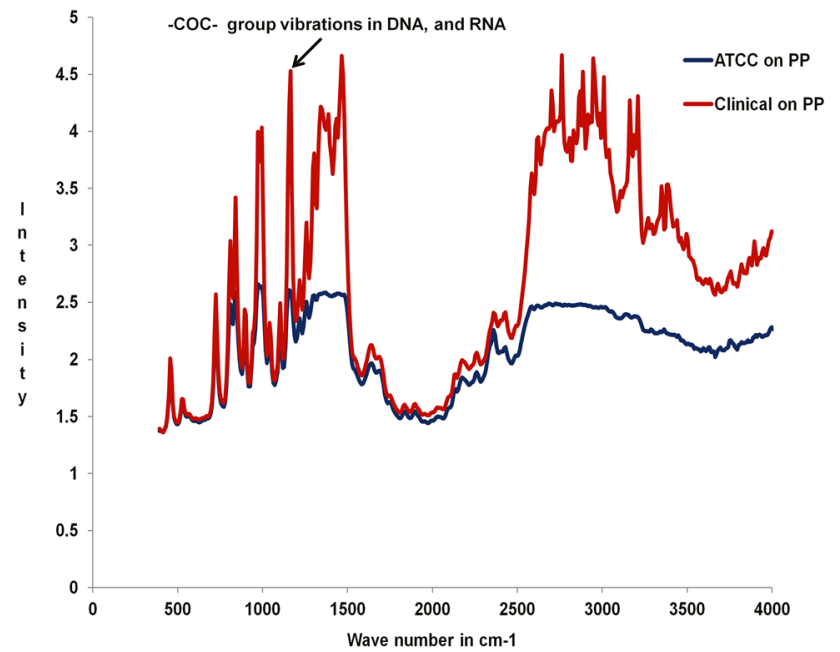

Fig. 3 FT-IR studies of biofilms produced by clinical and ATCC strains of $P$. aeruginosa on PP surface adsorbed with BSA for $24 \mathrm{~h}$

shown in Fig. 4a, b. The biofilms for both strains in this case have a undulating surface and dispersed biofilm bacteria are clearly visible in Fig. $4 a$, b. Both biofilms show abundant pores and channels typical of a true biofilm unlike that in Fig. 2b, which appears to be a stack of microbial cells and no trace of pores and channels on its surface. Another common feature revealed by the above images is the altered physiology of the biofilm bacteria on the HDPE surface. A comparison of biofilms in Figs. 2a, $b$ and $4 \mathrm{a}, \mathrm{b}$ demonstrate that bacterial cells of both the strains of $P$. aeruginosa react physiologically to the variations in the properties of the respective substrates, by altering their physical appearance and simultaneously regulating the nature and quantity of the secreted extracellular polymers. $P$. aeruginosa, which is normally a rod-shaped bacteria, as also observed in the biofilm on PP surface in Fig. 2a, transforms to a bean-shaped morphology, on HDPE surface adsorbed with BSA for $24 \mathrm{~h}$ as observed in Fig. 4a, b. Hence, both strains of bacteria possess an identical property of interacting in response to the substrates and in a similar way.

Hence, it can be concluded that comparison of the morphologies of the biofilms produced by the clinical and reference strains of $P$. aeruginosa on a PP surface adsorbed with BSA reveals a similarity in spreading and adhesion with the substrate, but they have visible differences in their respective architecture. On the other hand, the same strains of bacteria on HDPE surface adsorbed with BSA produce biofilms which have similar adhesive and morphological
Fig. 4 FESEM images of 7-day old biofilms of $P$. aeruginosa with a clinical strain, b ATCC strain

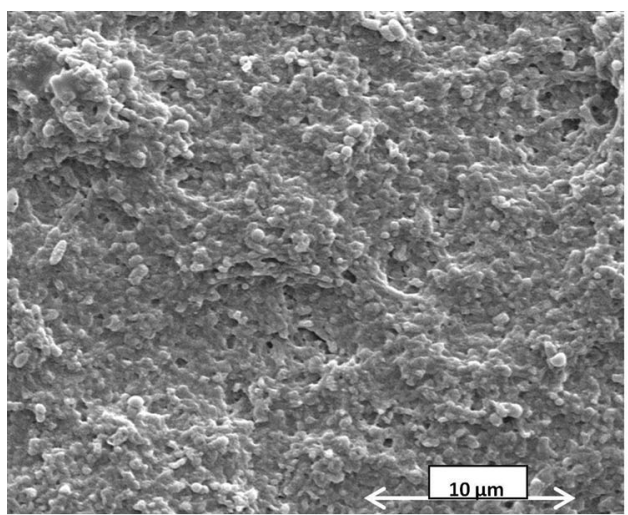

(a)

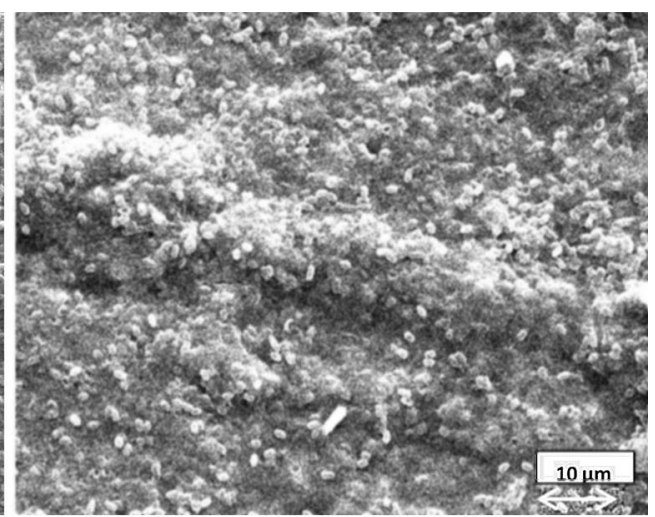

(b) 


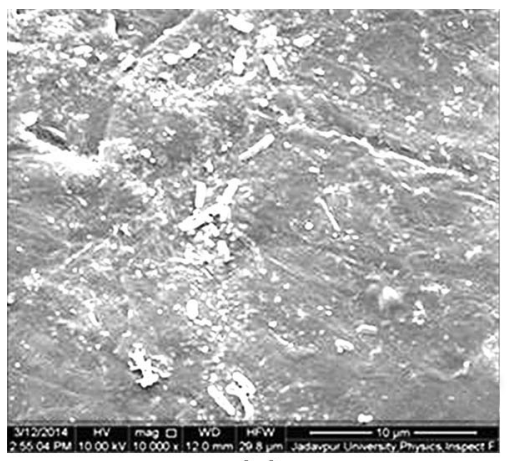

(a)

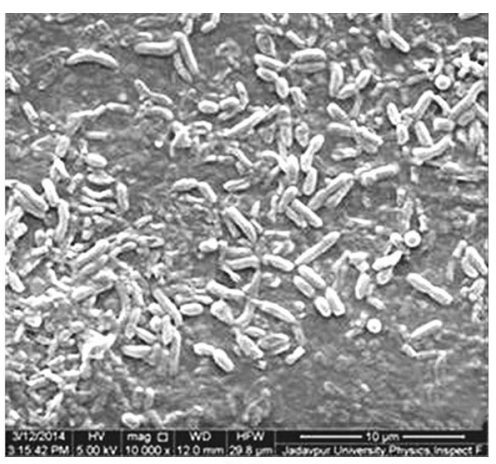

(b)

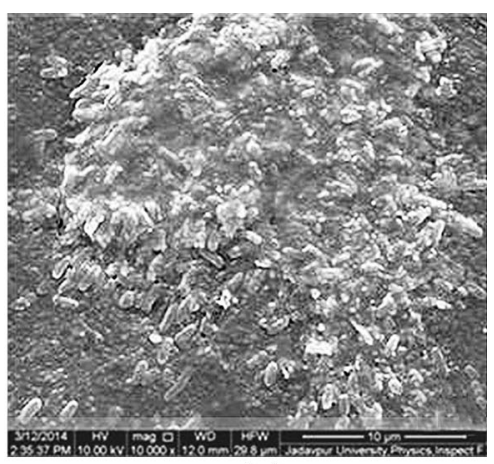

(c)

Fig. 5 FESEM images of 7-day old biofilms of $P$. aeruginosa on PP surface. a Bare surface, $\mathbf{b}$ with BSA adsorbed for 9 h, $\mathbf{c}$ with BSA adsorbed for $24 \mathrm{~h}$

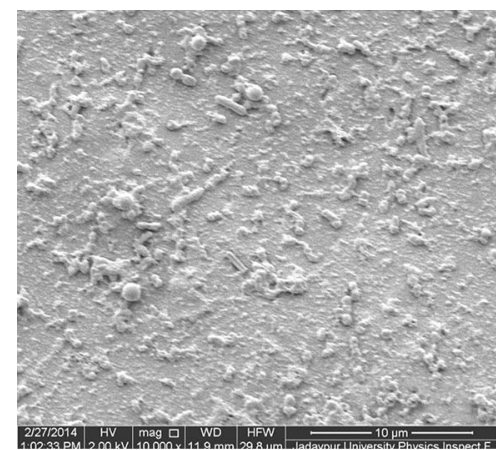

(a)

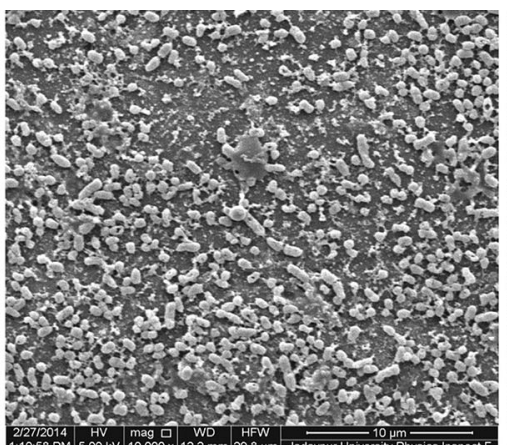

(b)

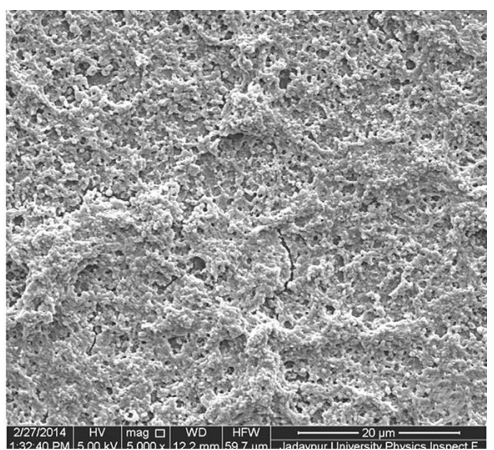

(c)

Fig. 6 FESEM images of 7-day old biofilms of $P$. aeruginosa on HDPE surface. a On the bare surface, $\mathbf{b}$ with BSA adsorbed for $9 \mathrm{~h}$, $\mathbf{c}$ with BSA adsorbed for $24 \mathrm{~h}$

properties. The FTIR data in Fig. 3 reveal that though the chemical constituents of the EPS matrices for both the strains on the PP surface are roughly similar, the amount of bacteria embedded within the biofilms grossly differs.

\section{Effect of adsorption time}

The FESEM images of the biofilms formed by the clinical strain of $P$. aeruginosa, on a pristine PP surface and on those adsorbed with BSA for 9 and $24 \mathrm{~h}$ duration, are shown in Fig. 5a-c.

FE-SEM images of the biofilms of the same strains of bacteria and of similar age on pristine HDPE surface, and on those adsorbed with BSA for 9 and $24 \mathrm{~h}$, are shown in Fig. 6a-c. Comparison of the biofilms in the respective situations in Figs. 5 and 6 reveals differences in their architecture in response to different substrates. However, repetition of biofilm growth on similar situations yields identical results.

The two-dimensional surface profiles (performed with Image J) of bare PP and HDPE surfaces (Fig SI 4, Supplementary Information) reveal differences of the order of
5-7\% between the two, proving that they possess roughly similar topography. A comparison between the two-dimensional surface profiles of the 7-day old biofilms formed by the clinical strain of $P$. aeruginosa, on HDPE and PP adsorbed with BSA for $24 \mathrm{~h}$ (Fig SI 5, Supplementary Information), indicate a roughly uniform spread of the biofilm on the HDPE surface in contrast to a 'focal adhesion' in case of PP surface. The biofilm bacteria, however, followed the same trend on both the substrates, i.e., (biofilm formed on pristine surface) $<$ (biofilm formed on BSA covered surface).

Apart from the prevalent biofilm architecture of P. aeruginosa ATCC 27853 on the PP surface as depicted in Fig. 2, parts of the substrate are found to be covered with patches of dendritic bacterial growth as shown in Fig. 7. However, the normal biofilm architecture on PP is never accompanied or interspersed by the dendritic patterns but each patch happens to occur at distinctly different areas of the substrate. The biofilm of the clinical strain, however, does not have any fragment of dendritic growth throughout the PP substrate. 


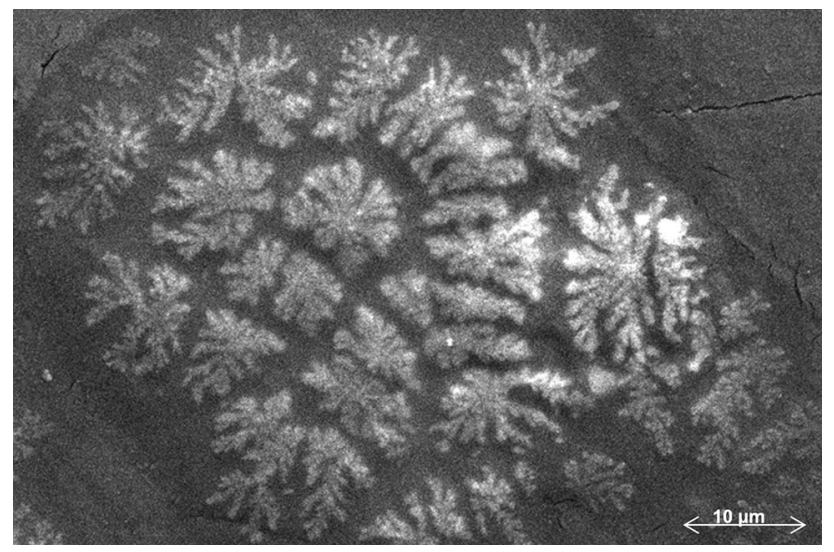

Fig. 7 Patches of dendritic patterns of bacterial growth found on PP surface adsorbed with BSA apart from biofilm covered areas

This phenomenon is also totally absent in ATCC/clinical strain biofilms on HDPE, where the biofilm morphology remains almost uniform (Fig. 4b) throughout the substrate.

\section{Discussion}

The phenomena observed during the adsorption experiments on PP and HDPE surfaces (Fig SI 1 and Fig SI 2, Supplementary Information) can be explained in terms of hydrophobicities of the respective biomaterials and the strength of the non-covalent interactions between the biomaterial surfaces and the adsorbed protein layer. PP is more hydrophobic than HDPE, and the soft protein BSA prefers the PP surface more than HDPE which may also be supported from the perspective of critical surface tension (Baier 2006). PP has higher water contact angle compared to HDPE (Table 1), but its critical surface tension is lower than HDPE causing greater affinity for the adsorption of BSA on it. Also the water contact angle on PP adsorbed with BSA for 9 and $24 \mathrm{~h}$ are less than that on HDPE for similar adsorption times. In general, hydrophobic interaction significantly contributes to protein adsorption on a surface. By modifying the hydrophobic polystyrene latex surface to hydrophilic, the amount of BSA adsorbed was found to decrease (Nakanishi et al. 2001; Imamura et al. 2008; Alava et al. 2013).

It is clearly evident from our experiments that the adsorbed protein, the strain of biofilm forming bacteria and

Table 1 Variation of water contact angles with adsorption of BSA

\begin{tabular}{llll}
\hline Polymers (clinical grade) & \multicolumn{4}{l}{ Contact angles } \\
\cline { 2 - 4 } & Bare & BSA 9 h & BSA 24 h \\
\hline PP & 96.6865 & 93.746 & 87.22565 \\
HDPE & 95.2918 & 94.39885 & 92.97118 \\
\hline
\end{tabular}

exposure time $\tau$, though same in the Figs. $2 \mathrm{a}$ and $4 \mathrm{a}$ and also in Figs. $2 b$ and $4 b$, the cumulative properties of the substrate (surface with adsorbed BSA) grossly affect not only the morphology of the biofilm but also the anatomical and physiological features of the biofilm-forming bacteria in each case. The biofilm images in Figs. 5 and 6 separately reveal the effect of the exposure time $\tau$. A comparison of the biofilms in the respective situations in Figs. 5 and 6 reveals a complete variation of biofilm architecture on the two substrates. The reason for variation in biofilm architecture on two different substrates under similar circumstances (such as strain of bacteria, conditioning layer, temperature, $\mathrm{pH}$, and amount of shear stress) may be related not only to the differences in water contact angles on BSA-adsorbed PP and HDPE (refer Table 1), but also to the distinction in the nature of the interfacial properties of the substrates and substrate-microbe interactions. In biological systems, hydrophobic interactions are specifically the strongest long-range non-covalent interactions (van Oss 1997). Such interactions can be defined as the primary attraction between apolar or slightly polar molecules, particles or cells, when immersed in water and the hydrogen bonding energy of cohesion between the surrounding water molecules forms the sole driving force for this interaction. The residual hydration of HDPE (i.e., the Lewis AB forces) is responsible for the orientation of water molecules adsorbed on its surface. Hence, water molecules oriented on its surface will repel the water molecules having same orientation on the surface of adjacent particles (van Oss and Good 1991; Carvalho, et al. 2013) preventing complete adhesion. On the other hand, the bacterial cell surfaces, which are less polar (i.e., capacity for orienting the most closely adsorbed water molecules is less pronounced), approach each other under the influence of their net Lifshitz-van der Waals (LW) attraction forming a close network and robust biofilm. On the PP surface, however, the biofilm-substrate adhesion is extremely pronounced, due to its greater hydrophilicity after BSA adsorption (Table 1) than HDPE and squeezing out of water molecules from its surface during protein adsorption. Hence, biofilm-substrate adhesion in PP exceeds intercellular attraction as is evident from Fig. 4c. The above analysis explains the difference in the biofilm architecture observed on HDPE and PP surfaces.

Our experimental results lead us to conclude that there is a significant contribution of both the substrate and conditioning layer on the biofilm architecture, which may affect the degree of attachment of the bacteria to the respective biomaterial surfaces. The above two factors controlling biofilm architecture are also found to modulate the bacterial physiology, which might play a significant role in altering their pathogenicities and toxicities, apart from their EPS producing capacities. Such an attribute is impossible 
in a planktonic bacterium forming a colony on different substrates. It is thus imminent that the macromolecular components of the bacterial cell surfaces, e.g., lipopolysaccharide and protein, and exopolymers secreted during biofilm formation possibly vary in quantity and chemical composition with the variation in the interfacial properties of the substrate and the microbial receptors interact with the substrate accordingly varying their physical form. This clearly indicates a combined role of both the adsorbed protein and the biomaterial surface in altering the physiology of the biofilm-forming bacteria.

The appearance of patches of dendritic growth in the $P$. aeruginosa ATCC strain biofilm on the BSA-covered PP substrate is an interesting phenomenon and may be analyzed from the point of view of rhamnolipid production and display of group behavior. Pseudomonas aeruginosa is capable of twitching, swimming, and swarming motility (Caiazza et al. 2005). Among these, swarming motility is a group behavior that requires rhamnolipid biosynthesis. The result of swarming in P. aeruginosa is the complex patterns of cells organized as radiating tendrils, the spaces between which may be analogous to biofilm channels in that they remain uncolonized. It has been noticed in swarming experiments that tendrils of a given swarm rarely intersect, and furthermore, tendrils from different swarms change course as they approach each other (as in Fig. 1A in Caiazza et al. 2005). Also, when tendrils of opposing swarms approach, they change direction and swarm parallel to each other instead of crossing paths. The dendritic growth pattern in Fig. 7 reveals a similar characteristic as described above, indicating the probability of production of rhamnolipids in the ATCC biofilm on PP substrate. Such occurrence has not been observed in either of the other bacteria-substrate interactions presented here. The reason for the rhamnolipid production on a particular substrate or for a particular bacteria-substrate pair is, however, not known at present and may be revealed through future research. However, it might be predicted that the presence of rhamnolipids in the EPS of a biofilm is able to change the biofilm architecture due to their tensioactive properties (Beal and Betts 2000).

\section{Conclusions}

In our experiments, the degree of adsorbed BSA is found to play a significant role in the growth and adhesion of the $P$. aeruginosa biofilm on both PP and HDPE. However, previous observations revealed that albumin is normally associated with inhibition of biofilm formation (An and Friedman 1998). Coating of polystyrene plates with Human serum albumin (HSA) was found to significantly reduce bacterial adhesion and biofilm formation in S. pneumonia (del Prado et al. 2010). But a few experimental evidence exist which reveal that anti-adherence effect is speciesdependent, as albumin coating of titanium surfaces decreased the adhesion of $S$. mutans, but adhesion of $P$. gingivalis and $F$. nucleatum remained unaffected (Badihi Hauslich et al. 2013). This latter trend may be in agreement with our observations with both clinical and reference strains of $P$. aeruginosa.

It is hence evident that for $P$. aeruginosa, the nature of the substrate and conditioning layer regulates the possibility of formation, architecture, and adhesion of biofilms to medical implants, giving rise to acute biomaterial-associated infections (BAIs). A dense biofilm shown in Figs. $5 \mathrm{c}$ and $6 \mathrm{c}$ brings forth the vulnerability of infection in orthopedic implants and venous catheters. Moreover, greater volume of EPS of the biofilm ensures greater chance of thrombus formation within the blood vessels, after the maturation and detachment of the biofilm from the implant surface. The biofilms formed by the clinically isolated strain also prove beyond doubt that a strain of bacteria forming biofilms on urinary catheters (i.e., on silicon rubber) is equally capable of forming biofilms on any other substrate. Hence, while it is well known that $P$. aeruginosa is responsible for causing cystic fibrosis (CF), urinary infections, otitis media, and burn infections, it is quite obvious from our experiments, that the same pathogen might infect orthopedic implants or central venous catheters if it gets access to the same.

We can, hence, conclude from our studies that the bacterial receptors are able to identify the differences in the properties of the substrates, and modulate their genetic expressions accordingly. The mechanism of interaction may be different for different bacteria-biomaterial-protein combinations but the understanding obtained by various available techniques (Fattinger 2014; Vo-Dinh 2014) would further increase the existing knowledge of prevention of biofilm formation on implants. The alteration in the physiology of the biofilm-forming bacteria on encountering different substrates might be linked to a change in its genetic expression and not an emergence of a new genome. Further, gene sequencing studies in this regard will reveal the truth of this hypothesis. Employing further strategic studies and intensive research in this area in future might enable the creation of superb biomaterial surfaces that would be able to modulate the genetic expression of bacteria to a non-biofilm mode, irrespective of adsorbed conditioning layer.

Acknowledgements Dr. S Dutta Sinha is thankful to Department of Science and Technology, Govt. of India for funding the research through the Women's Scientist Scheme (WOS-A) (Project: DST: SR/ WOS-A/LS-466/2013) and Jadavpur University, Kolkata for providing infrastructural and other supports, without which the present research would not have been possible. S Dutta Sinha is thankful to 
Prof. Dr. Pratip Kundu, of School of Tropical Medicine, Kolkata, for his helpful suggestions and support and to Dr. Debkishore Gupta for providing the sample of reference strain of bacteria.

Open Access This article is distributed under the terms of the Creative Commons Attribution 4.0 International License (http://crea tivecommons.org/licenses/by/4.0/), which permits unrestricted use, distribution, and reproduction in any medium, provided you give appropriate credit to the original author(s) and the source, provide a link to the Creative Commons license, and indicate if changes were made.

\section{References}

Alava T, Mann JA, Théodore C, Benitez JJ, Dichtel WR, Parpia JM, Craighead HG (2013) Control of the graphene-protein interface is required to preserve adsorbed protein function. Anal Chem 85(5):2754-2759

Almaguer-Flores A, Olivares-Navarrete R, Wieland M, XiménezFyvie LA, Schwartz Z, Boyan BD (2012) Influence of topography and hydrophilicity on initial oral biofilm formation on microstructured titanium surfaces in vitro. Clin Oral Implant Res 23(3):301-307

Alpkvist E, Picioreanu C, van Loosdrecht M, Heyden A (2006) Three-dimensional biofilm model with individual cells and continuum EPS matrix. Biotechnol Bioeng 94(5):961-979. doi:10.1002/bit.20917

Amiji M, Park K (1993) Surface modification of polymeric biomaterials with poly(ethylene oxide), albumin, and heparin for reduced thrombogenicity. J Biomater Sci Polym Ed 4(3):217-234. doi:10.1163/156856293X00537

An YH, Friedman RJ (1998) Concise review of mechanisms of bacterial adhesion to biomaterial surfaces. J Biomed Mater Res 43(3):338-348

Badihi Hauslich L, Sela MN, Steinberg D, Rosen G, Kohavi D (2013) The adhesion of oral bacteria to modified titanium surfaces: role of plasma proteins and electrostatic forces. Clin Oral Implant Res 24(A100):49-56. doi:10.1111/j.1600-0501.2011.02364.x

Baier RE (2006) Surface behaviour of biomaterials: the theta surface for biocompatibility. J Mater Sci Mater Med 17(11):1057-1062. doi:10.1007/s10856-006-0444-8

Bakker DP, Klijnstra JW, Busscher HJ, van der Mei HC (2003) The effect of dissolved organic carbon on bacterial adhesion to conditioning films adsorbed on glass from natural seawater collected during different seasons. Biofouling 19(6):391-407

Beal R, Betts WB (2000) Role of rhamnolipid biosurfactants in the uptake and mineralization of hexadecane in Pseudomonas aeruginosa. J Appl Microbiol 89(1):158-168

Beyenal H, Lewandowski Z (2000) Combined effect of substrate concentration and flow velocity on effective diffusivity in biofilms. Water Res 34(2):528-538

Bhosle NB, Garg A, Fernandes L, Citon P (2005) Dynamics of amino acids in the conditioning film developed on glass panels immersed in the surface seawaters of Dona Paula Bay. Biofouling 21(2):99-107. doi:10.1080/08927010500097821

Boulmedais F, Frisch B, Etienne O, Lavalle P, Picart C, Ogier J et al (2004) Polyelectrolyte multilayer films with pegylated polypeptides as a new type of anti-microbial protection for biomaterials. Biomaterials 25(11):2003-2011

Bowden GHW, Li YH (1997) Nutritional influences on biofilm development. Adv Dent Res 11(1):81-99

Branda SS, Vik Å, Friedman L, Kolter R (2005) Biofilms: the matrix revisited. Trends Microbiol 13(1):20-26. doi:10.1016/j.tim.2004. 11.006
Caiazza NC, Shanks RM, O'Toole GA (2005) Rhamnolipids modulate swarming motility patterns of Pseudomonas aeruginosa. J Bacteriol 187(21):7351-7361

Campa M, Bendinelli M, Friedman H (eds) (2012) Pseudomonas aeruginosa as an opportunistic pathogen. Springer Science \& Business Media, Berlin

Carvalho I, Henriques M, Carvalho S (2013) New strategies to fight bacterial adhesion. In: Microbial Pathogens and Strategies for Combating them: Science, Technology and Education, Formatex Research Center, p 170-178

Castner DG, Ratner BD (2002) Biomedical surface science: foundations to frontiers. Surf Sci 500(1):28-60. doi:10.1016/S00396028(01)01587-4

Chae KJ, Choi MJ, Lee JW, Kim KY, Kim IS (2009) Effect of different substrates on the performance, bacterial diversity, and bacterial viability in microbial fuel cells. Bioresour Technol 100(14):3518-3525

Chang CC, Merritt K (1992) Microbial adherence on poly(methyl methacrylate) (PMMA) surfaces. J Biomed Mater Res 26(2):197-207

Chu PK, Chen JY, Wang LP, Huang N (2002) Plasma-surface modification of biomaterials. Mater Sci Eng $R$ Rep 36(5):143-206

Compere C, Bellon-Fontaine MN, Bertrand P, Costa D, Marcus P, Poleunis C, Pradier CM, Rondot B, Walls MG (2001) Kinetics of conditioning layer formation on stainless steel immersed in seawater. Biofouling 17(2):129-145

Costerton JW, Stewart PS, Greenberg EP (1999) Bacterial biofilms: a common cause of persistent infections. Science 284(5418):1318-1322

Dang H, Lovell CR (2016) Microbial surface colonization and biofilm development in marine environments. Microbiol Mol Biol Rev 80(1):91-138. doi:10.1128/MMBR.00037-15

de Paz LEC, Bergenholtz G, Svensäter G (2010) The effects of antimicrobials on endodontic biofilm bacteria. $\mathrm{J}$ Endod 36(1):70-77

del Prado G, Ruiz V, Naves P, Rodríguez-Cerrato V, Soriano F, del Carmen PM (2010) Biofilm formation by Streptococcus pneumoniae strains and effects of human serum albumin, ibuprofen, $\mathrm{N}$-acetyl-L-cysteine, amoxicillin, erythromycin, and levofloxacin. Diagn Microbiol Infect Dis 67(4):311-318. doi:10.1016/j. diagmicrobio.2010.03.016

Dewez JL, Doren A, Schneider YJ, Rouxhet PG (1999) Competitive adsorption of proteins: key of the relationship between substratum surface properties and adhesion of epithelial cells. Biomaterials 20(6):547-559. doi:10.1016/S0142-9612(98)00207-5

Donlan RM (2001) Biofilm formation: a clinically relevant microbiological process. Clin Infect Dis 33(8):1387-1392. doi:10.1086/ 322972

Etienne O, Gasnier C, Taddei C, Voegel JC, Aunis D, Schaaf P et al (2005) Antifungal coating by biofunctionalized polyelectrolyte multilayered films. Biomaterials 26(33):6704-6712

Falkinham JO III, Hilborn ED, Arduino MJ, Pruden A, Edwards MA (2015) Epidemiology and ecology of opportunistic premise plumbing pathogens: Legionella pneumophila, Mycobacterium avium, and Pseudomonas aeruginosa. Environ Health Perspect 123(8):749. doi:10.1289/ehp.1408692

Fattinger C (2014) Focal molography: coherent microscopic detection of biomolecular interaction. Phys Rev X 4(3):031024

Flemming HC, Wingender J (2010) The biofilm matrix. Nat Rev Microbiol 8(9):623-633. doi:10.1038/nrmicro2415

Flemming HC, Neu TR, Wozniak DJ (2007) The EPS matrix: the "house of biofilm cells". J Bacteriol 189(22):7945-7947. doi:10. 1128/JB.00858-07

Foster TJ (2005) Immune evasion by staphylococci. Nat Rev Microbiol 3(12):948-958. doi:10.1038/nrmicro128 
Freeman C, Lock MA (1995) The biofilm polysaccharide matrix: a buffer against changing organic substrate supply? Limnol Oceanogr 40(2):273-278

Garrett TR, Bhakoo M, Zhang Z (2008) Bacterial adhesion and biofilms on surfaces. Prog Nat Sci 18(9):1049-1056. doi:10. 1016/j.pnsc.2008.04.001

Haggag WM (2010) The role of biofilm exopolysaccharides on biocontrol of plant diseases. In: Elnashar M (ed) Biopolymers, InTech, Rijeka, Croatia, p 271-284, ISBN: 978-953-307-109-1

Hetrick EM, Schoenfisch MH (2006) Reducing implant-related infections: active release strategies. Chem Soc Rev 35(9):780-789. doi:10.1039/b515219b

Hochbaum AI, Kolodkin-Gal I, Foulston L, Kolter R, Aizenberg J, Losick R (2011) Inhibitory effects of D-amino acids on Staphylococcus aureus biofilm development. J Bacteriol 193(20):5616-5622

Høiby N, Bjarnsholt T, Givskov M, Molin S, Ciofu O (2010) Antibiotic resistance of bacterial biofilms. Int $\mathrm{J}$ Antimicrob Agents 35(4):322-332. doi:10.1016/j.ijantimicag.2009.12.011

Hori K, Matsumoto S (2010) Bacterial adhesion: from mechanism to control. Biochem Eng J 48(3):424-434. doi:10.1016/j.bej.2009. 11.014

Hornef MW, Wick MJ, Rhen M, Normark S (2002) Bacterial strategies for overcoming host innate and adaptive immune responses. Nat Immunol 3(11):1033-1040. doi:10.1038/ni11021033

Huang Y, Leobandung W, Foss A, Peppas NA (2000) Molecular aspects of muco-and bioadhesion: tethered structures and sitespecific surfaces. J Controlled Release 65(1):63-71

Ignatova $\mathrm{M}$, Voccia $\mathrm{S}$, Gilbert $\mathrm{B}$, Markova $\mathrm{N}$, Cossement $\mathrm{D}$, Gouttebaron R et al (2006) Combination of electrografting and atom-transfer radical polymerization for making the stainless steel surface antibacterial and protein antiadhesive. Langmuir 22(1):255-262

Imamura K, Shimomura M, Nagai S, Akamatsu M, Nakanishi K (2008) Adsorption characteristics of various proteins to a titanium surface. J Biosci Bioeng 106(3):273-278

Jiao Y, Cody GD, Harding AK, Wilmes P, Schrenk M, Wheeler KE et al (2010) Characterization of extracellular polymeric substances from acidophilic microbial biofilms. Appl Environ Microbiol 76(9):2916-2922. doi:10.1128/AEM.02289-09

Kiehn TE, Armstrong D (1990) Changes in the spectrum of organisms causing bacteremia and fungemia in immunocompromised patients due to venous access devices. Eur J Clin Microbiol Infect Dis 9(12):869-872. doi:10.1007/BF01967501

Kohnen W, Kolbenschlag C, Teske-Keiser S, Jansen B (2003) Development of a long-lasting ventricular catheter impregnated with a combination of antibiotics. Biomaterials 24(26):4865-4869

Kugaprasatham S, Nagaoka H, Ohgaki S (1992) Effect of turbulence on nitrifying biofilms at non-limiting substrate conditions. Water Res 26(12):1629-1638

Lee B, Haagensen JA, Ciofu O, Andersen JB, Høiby N, Molin S (2005) Heterogeneity of biofilms formed by nonmucoid Pseudomonas aeruginosa isolates from patients with cystic fibrosis. J Clin Microbiol 43(10):5247-5255

Leonard EF, Vroman L (1992) Is the Vroman effect of importance in the interaction of blood with artificial materials? J Biomater Sci Polym Ed 3(1):95-107. doi:10.1163/156856292X00105

Li Z, Lee D, Sheng X, Cohen RE, Rubner MF (2006) Two-level antibacterial coating with both release-killing and contact-killing capabilities. Langmuir 22(24):9820-9823

Li G, Brown PJ, Tang JX, Xu J, Quardokus EM, Fuqua C, Brun YV (2012) Surface contact stimulates the just-in-time deployment of bacterial adhesins. Mol Microbiol 83(1):41-51. doi:10.1111/j. 1365-2958.2011.07909.x
Liu J, Fu S, Yuan B, Li Y, Deng Z (2010) Toward a universal "adhesive nanosheet" for the assembly of multiple nanoparticles based on a protein-induced reduction/decoration of graphene oxide. J Am Chem Soc 132(21):7279-7281. doi:10.1021/ ja100938r

Lynch AS, Robertson GT (2008) Bacterial and fungal biofilm infections. Annu Rev Med 59:415-428. doi:10.1146/annurev. med.59.110106.132000

Mah TFC, O'Toole GA (2001) Mechanisms of biofilm resistance to antimicrobial agents. Trends Microbiol 9(1):34-39. doi:10.1016/ S0966-842X(00)01913-2

Nakanishi K, Sakiyama T, Imamura K (2001) On the adsorption of proteins on solid surfaces, a common but very complicated phenomenon. J Biosci Bioeng 91(3):233-244. doi:10.1016/ S1389-1723(01)80127-4

Oberhardt MA, Puchałka J, Fryer KE, Dos Santos VA, Papin JA (2008) Genome-scale metabolic network analysis of the opportunistic pathogen Pseudomonas aeruginosa PAO1. J Bacteriol 190(8):2790-2803. doi:10.1128/JB.01583-07

Peyton BM (1996) Effects of shear stress and substrate loading rate on Pseudomonas aeruginosa biofilm thickness and density. Water Res 30(1):29-36

Rios PF, Dodiuk H, Kenig S, McCarthy S, Dotan A (2007) The effect of polymer surface on the wetting and adhesion of liquid systems. J Adhes Sci Technol 21(3-4):227-241

Roy-Burman A, Savel RH, Racine S, Swanson BL, Revadigar NS, Fujimoto J, Sawa T, Frank DW, Wiener-Kronish JP (2001) Type III protein secretion is associated with death in lower respiratory and systemic Pseudomonas aeruginosa infections. J Infect Dis 183(12):1767-1774. doi:10.1086/320737

Rudra JS, Dave K, Haynie DT (2006) Antimicrobial polypeptide multilayer nanocoatings. J Biomater Sci Polym Ed 17(11):1301-1315

Salta M, Wharton JA, Blache Y, Stokes KR, Briand JF (2013) Marine biofilms on artificial surfaces: structure and dynamics. Environ Microbiol 15(11):2879-2893. doi:10.1111/1462-2920.12186

Saygun O, Agalar C, Aydinuraz K, Agalar F, Daphan C, Saygun M (2006) Gold and gold-palladium coated polypropylene grafts in a S. epidermidis wound infection model. J Surg Res 131(1):73-79

Stewart PS, Costerton JW (2001) Antibiotic resistance of bacteria in biofilms. The Lancet 358(9276):135-138. doi:10.1016/S01406736(01)05321-1

Stoodley P, Boyle JD, Dodds I, Lappin-Scott HM (1997) Consensus model of biofilm structure. In: Wimpenny JWT, Handley PS, Gilbert P, Lappin-Scott HM, Jones M (eds) Biofilms: community interactions and controls, BioLine, Cardiff, U.K, p 1-9

Tang CJ, Zheng P, Hu BL, Chen JW, Wang CH (2010) Influence of substrates on nitrogen removal performance and microbiology of anaerobic ammonium oxidation by operating two UASB reactors fed with different substrate levels. J Hazard Mater 181(1):19-26

Tiller JC, Lee SB, Lewis K, Klibanov AM (2002) Polymer surfaces derivatized with poly(vinyl- $N$-hexylpyridinium) kill airborne and waterborne bacteria. Biotechnol Bioeng 79(4):465-471

Tuson HH, Weibel DB (2013) Bacteria-surface interactions. Soft Matter 9(17):4368-4380. doi:10.1039/C3SM27705D

van Oss CJ (1997) Hydrophobicity and hydrophilicity of biosurfaces. Curr Opin Colloid Interface Sci 2(5):503-512. doi:10.1016/ S1359-0294(97)80099-4

van Oss CJ, Good BJ (1991) Surface enthalpy and entropy and the physico-chemical nature of hydrophobic and hydrophilic interactions. J Dispers Sci Technol 12(3-4):273-287. doi:10.1080/ 01932699108913130

Vo-Dinh T (ed) (2014) Biomedical photonics handbook: biomedical diagnostics. CRC Press, Boca Raton

Vogler EA (2012) Protein adsorption in three dimensions. Biomaterials 33(5):1201-1237. doi:10.1016/j.biomaterials.2011.10.059 
von Eiff C, Jansen B, Kohnen W, Becker K (2005) Infections associated with medical devices. Drugs 65(2):179-214

Vu B, Chen M, Crawford RJ, Ivanova EP (2009) Bacterial extracellular polysaccharides involved in biofilm formation. Molecules 14(7):2535-2554. doi:10.3390/molecules14072535

Waldvogel FA, Bisno AL (2000) Infections associated with indwelling medical devices, 3rd edn. ASM Press, Washington DC

Weinstein RA, Darouiche RO (2001) Device-associated infections: a macroproblem that starts with microadherence. Clin Infect Dis 33(9):1567-1572. doi:10.1086/323130

Whiteley M, Bangera MG, Bumgarner RE, Parsek MR, Teitzel GM, Lory S, Greenberg EP (2001) Gene expression in Pseudomonas aeruginosa biofilms. Nature 413(6858):860-864. doi:10.1038/ 3510162
Wimpenny JW, Colasanti R (1997) A unifying hypothesis for the structure of microbial biofilms based on cellular automaton models. FEMS Microbiol Ecol 22(1):1-16

Wingender J, Neu TR, Flemming HC (eds) (2012) Microbial extracellular polymeric substances: characterization, structure and function. Springer Science \& Business Media, Berlin

Zhang X, Bishop PL, Kinkle BK (1999) Comparison of extraction methods for quantifying extracellular polymers in biofilms. Water Sci Technol 39(7):211-218

Zhu X, Suidan MT, Pruden A, Yang C, Alonso C, Kim BJ, Kim BR (2004) Effect of substrate Henry's constant on biofilter performance. J Air Waste Manag Assoc 54(4):409-418 